\title{
Preparation and evaluation of demulsifiers agents for Basra crude oil
}

\author{
Hikmeat Abd Al-Raheem Ali
}

Received: 2 July 2011/ Accepted: 23 November 2011/Published online: 6 March 2012

(c) The Author(s) 2012. This article is published with open access at Springerlink.com

\begin{abstract}
The present study relates to the preparation of demulsifiers from caster oil for dehydration (desalting) of Basra crude oil and water emulsions. It is an empirical application study. Two emulsifiers were compared, $\mathrm{R}_{\mathrm{P}} /$ 6000, which is commercially available and ammonium castor oil sulfonate that was prepared. The general physical properties and IR spectra were measured for the demulsifiers. The demulsification studies were performed at $50{ }^{\circ} \mathrm{C}$, using a water-oil emulsion containing 15 vol\% water and 3 wt $\% \mathrm{NaCl}$ in the water. Parameters that were studied include demulsification time, demulsifier dose and the effect of $\mathrm{pH}$. The best water separation was obtained at highest $\mathrm{pH}$ and demulsifier dose.
\end{abstract}

Keywords Demulsifiers · Basra crude oil

\section{Introduction}

Demulsifing agents are employed to break emulsions of polar solutes like water and nonpolar solutes like oil. They are used in functional fluids (for example, metal removal fluids, rust and oxidation fluids and transformer fluids) to inhibit the formation of emulsions and break emulsions that have developed (Golden 2003).

Among their industrial uses, demulsifiers are commonly used to dehydrate and desalt of crude oil (Berger and Hsu 2000). Salts and suspended matter are present in crude oil in varying concentrations, depending on the area where the oil originated. The water and crude oil emulsions are

H. A. A.-R. Ali $(\square)$

Polymer Research Center, University of Basrah, Basrah, Iraq e-mail: hakmatali@yahoo.com formed naturally or artificially, by washing with water in a desalting unit (Ptister and Antoine 2000). The content of these emulsion ranges from 0 to $5 \%$ by mass of the emulsion (Ptister and Antoine 2000). The breaking of the emulsion results in the formation of an aqueous phase containing salts and suspended matter and of an organic phase ("crude oil phase") containing the hydrocarbons (Durrieu and Havre 1992). The salts and water, unless removed, will cause problems in the distillation columns (Durrieu and Havre 1992; Hobson 1988). The salts present are the cause of corrosion observed in the production, transportation and refining of salt containing crude oils (Lorenz and Martin 1976; Kirk 1988). The water may also vaporize when exposed to high temperature, causing a rapid increase in pressure or even an explosion (Institute of Petroleum 1990; Gary and Handwerk 1975). It is consequently important to thoroughly remove water from crude oil before further refining, and demulsifiers play an important role in achieving this goal.

The present study investigates two demulsifing agents that are capable of aiding the separation of water and crude oil mixtures (Institute of Petroleum 1990). The one demulsifier, $R_{P} / 6000$, is commercially available, and the other demulsifier, ammonium caster oil sulfonate (ASC), was prepared in our laboratory. This is an application report and it is empirical in nature.

\section{Experimental work}

Materials and instruments

All experiments were conducted with Basra crude oil (Table 1). The other materials and instruments employed are listed below. 


\begin{tabular}{ll}
\hline Suppliers & Materials and instruments \\
\hline Iraq-Basrah oil company & Castor oil \\
Iraq-Basrah oil company & RP6000 \\
B.D.H & Sulfuric acid \\
Fluka & Sodium hydroxide \\
Fluka & Ammonia \\
Fluka & Toluene \\
Germany & Mechanical stirrer \\
India & Separating funnel \\
Studious & Water bath \\
Germany & Evaporation rotary \\
BOUCK & IR spectrum \\
India & Micro sarong \\
India & Conductivity meter \\
India & pH meter \\
\hline
\end{tabular}

Table 1 Physical properties of the Basra crude oil employed in this study

\begin{tabular}{ll}
\hline Property & Basra crude oil \\
\hline Specific gravity at $24{ }^{\circ} \mathrm{C}(\mathrm{g} / \mathrm{mL})$ & 0.8849 \\
Salt content $(\mathrm{wt} \%)$ & 0.0006 \\
Water and sediment content $(\mathrm{vol} \%)$ & 0.05 \\
Asphaltene content $(\mathrm{wt} \%)$ & 2.22 \\
Sulfur content $(\mathrm{wt} \%)$ & 2.1 \\
Viscosity at $20{ }^{\circ} \mathrm{C}(\mathrm{cP})$ & 50 \\
Conductivity $(\mathrm{mS})$ & 0 \\
API & 28.4 \\
\hline
\end{tabular}

Experimental procedure

\section{Surfactant preparation}

A mixture of $250 \mathrm{~mL}$ of caster oil and $50 \mathrm{~mL}$ of sulfuric acid were placed in a $500 \mathrm{~mL}$ three-neck round bottom flask, and the mixture was stirred for $3 \mathrm{~h}$ at room temperature. After the reaction, $50 \mathrm{~mL}$ of ammonia was added to the mixture and the mixture was heated to $80{ }^{\circ} \mathrm{C}$, while stirring for $4 \mathrm{~h}$. After the reaction completed, the mixture was transferred to a rotary evaporator to separate the water and any solvent that remained. This procedure was previously reported in the literature (Silverstein and Basslar 1981).

\section{Emulsion preparation}

The water in crude oil emulsion was prepared from crude oil by adding $30 \mathrm{vol} \%$ water to the oil at ambient temperature. The water contained $3 \%$ by mass sodium chloride $(\mathrm{NaCl})$. The emulsion was formed by stirring the two-phase mixture with a mixer at a speed of 5,000 revolutions per minute for $60 \mathrm{~min}$. This gave a good stable emulsion without showing any signs of flocculation. The rate of water separation was monitored for a period of up to $24 \mathrm{~h}$.

\section{Evaluation of water separation efficiency of demulsifiers (Bottle test)}

The demulsification tests were performed in $100 \mathrm{~mL}$ beakers all filled with the water and crude oil emulsion (w/o emulsion). In each beaker, the demulsifier was injected and mixed for one minute. The gravity separation of the water phase from the crude oil was allowed to take place while the temperature was kept constant at $50{ }^{\circ} \mathrm{C}$ using a temperature controlled water bath.

\section{Effect of demulsifiers on water separation efficiency}

In this set of experiments, the effect of ACS and $\mathrm{R}_{\mathrm{P}} / 6000$ was investigated. The doses of these compounds were 10 , 20, 30, 40 and $50 \mathrm{ppm}$.

\section{Measurements}

\section{Salt content}

The salt content in the crud oil was measured using a calibrated conductivity meter.

\section{pH measurements}

The acidity of the water that was separated from the w/o emulsion was measured using a $\mathrm{pH}$ meter that was calibrated with buffer solutions having a pH of 4, 7 and 9 , respectively.

\section{Residual water content}

The residual water content in the w/o emulsion after breaking the emulsion was evaluated using the Dean-Stark method. The apparatus consists of a round bottom flask $(500 \mathrm{~mL})$ connected to a Liebig condenser through a receiving tube.

\section{Density}

The emulsion density was evaluated using picnometer.

\section{Results and discussion}

Physical properties of the demulsifier

The physical properties (density, $\mathrm{pH}$, viscosity and flash point) of the ASC demulsifier were measured according to 
Table 2 Physical properties of the demulsifiers $\mathrm{R}_{\mathrm{P}} / 6000$ and ACS

\begin{tabular}{llllll}
\hline Demulsifier & Color & $\mathrm{pH}$ & $\begin{array}{l}\text { Flash } \\
\text { point }{ }^{\circ} \mathrm{C}\end{array}$ & $\begin{array}{l}\text { Viscosity } \\
(\mathrm{cSt})\end{array}$ & $\begin{array}{l}\text { Specific } \\
\text { gravity } \\
(\mathrm{g} / \mathrm{mL})\end{array}$ \\
\hline $\mathrm{R}_{\mathrm{P}} / 6000$ & Brown & 5.8 & 56 & 1.4905 & 0.8770 \\
$\mathrm{ACS}$ & Brown/Black & 6.7 & 60 & 1.4899 & 0.8766 \\
\hline
\end{tabular}

the applicable ASTM standards and compared with the reference demulsifier, $\mathrm{R}_{\mathrm{P}} / 6000$ (Table 2). It can be seen from Table 2 that the physical properties of ACS were similar to physical properties of $\mathrm{R}_{\mathrm{P}} / 6000$. The flash point of the ACS demulsifier was high to improve safety during handling and transfer of the demulsifier.

\section{Separation efficiency}

The effect of $R_{P} / 6000$ and ACS on water separation efficiency over time is shown in Figs. 1 and 2. Figure 1 shows an increase in water separation for $\mathrm{R}_{\mathrm{P}} / 6000$ until it reaches $60 \mathrm{~min}$, after that the separation levels off and the separation rate is low. The best separation recorded for $\mathrm{R}_{\mathrm{P}} / 6000$ was $87 \%$ after 120 min. Figure 2 shows an increase in water separation for ACS over time. The separation rate of water was high only for the first $30 \mathrm{~min}$, where after it decreased significantly. The best separation recorded for ACS was $85 \%$ after 120 min.

Both demulsifiers tested failed to improve separation beyond the threshold observed at $60 \mathrm{~min}$. This threshold value correlated with the demulsifier concentration. The minimal additional increase in separation after $60 \mathrm{~min}$ that was observed for $\mathrm{R}_{\mathrm{P}} / 6000$ and ACS is because the active chemical groups $\left(\mathrm{OH}, \mathrm{COOH}, \mathrm{C}=\mathrm{O}, \mathrm{OSO}_{2}, \mathrm{SO}_{2} \mathrm{OH}\right)$ on the hydrocarbons chains are fully engaged and are not available to improve separation.

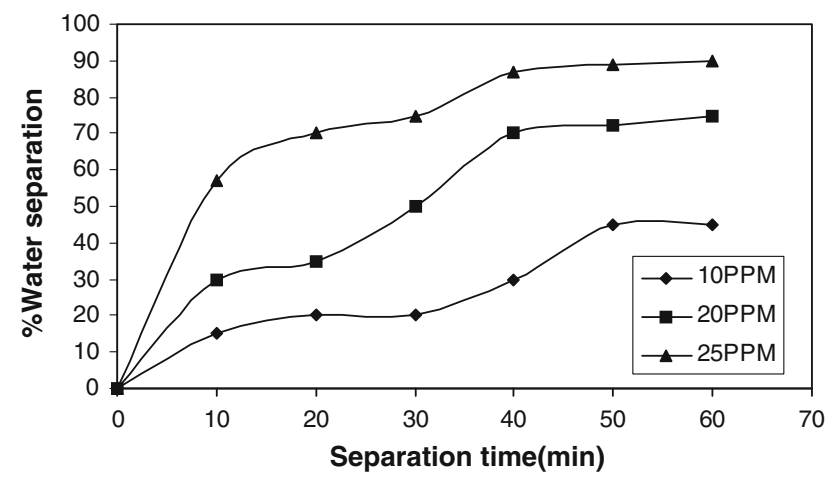

Fig. 1 The influence of various concentrations of $R_{P} / 6000$ on the separation of water. The water phase was 15 vol\% and the temperature was $50^{\circ} \mathrm{C}$

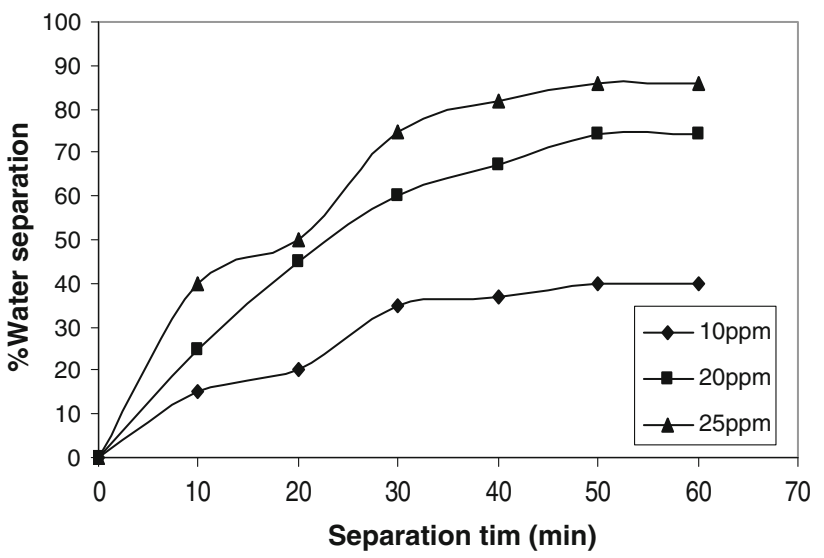

Fig. 2 The influence of various concentrations of ACS on the separation of water. The water phase was 15 vol\% and the temperature was $50{ }^{\circ} \mathrm{C}$

Effect of $\mathrm{pH}$ on separation efficiency

The effect of $\mathrm{pH}$ value on separation efficiency is shown in Fig. 3. Over the $\mathrm{pH}$ range tested, the separation increased monotonically with an increase in $\mathrm{pH}$, and the best separation was achieved at higher $\mathrm{pH}$. The limiting values were the same as reported before.

Characterization of the prepared demulsifier

The infrared (IR) spectra of caster oil (Fig. 4) and the ACS demulsifier (Fig. 5) are shown for comparison. The unmodified castor oil does not exhibit the sulfur- and nitrogen-related absorption bands found in the ACS (Table 3).

\section{Conclusions}

The present study is an application report and is empirical in nature. The following conclusions could be drawn from

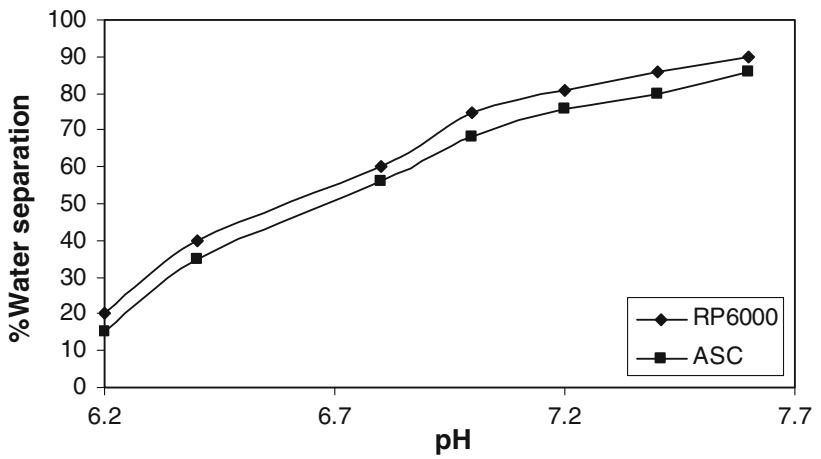

Fig. 3 Effect of $\mathrm{pH}$ on the water separation efficiency using $\mathrm{R}_{\mathrm{P}} / 6000$ and ACS 
Fig. 4 Infrared spectrum of caster oil

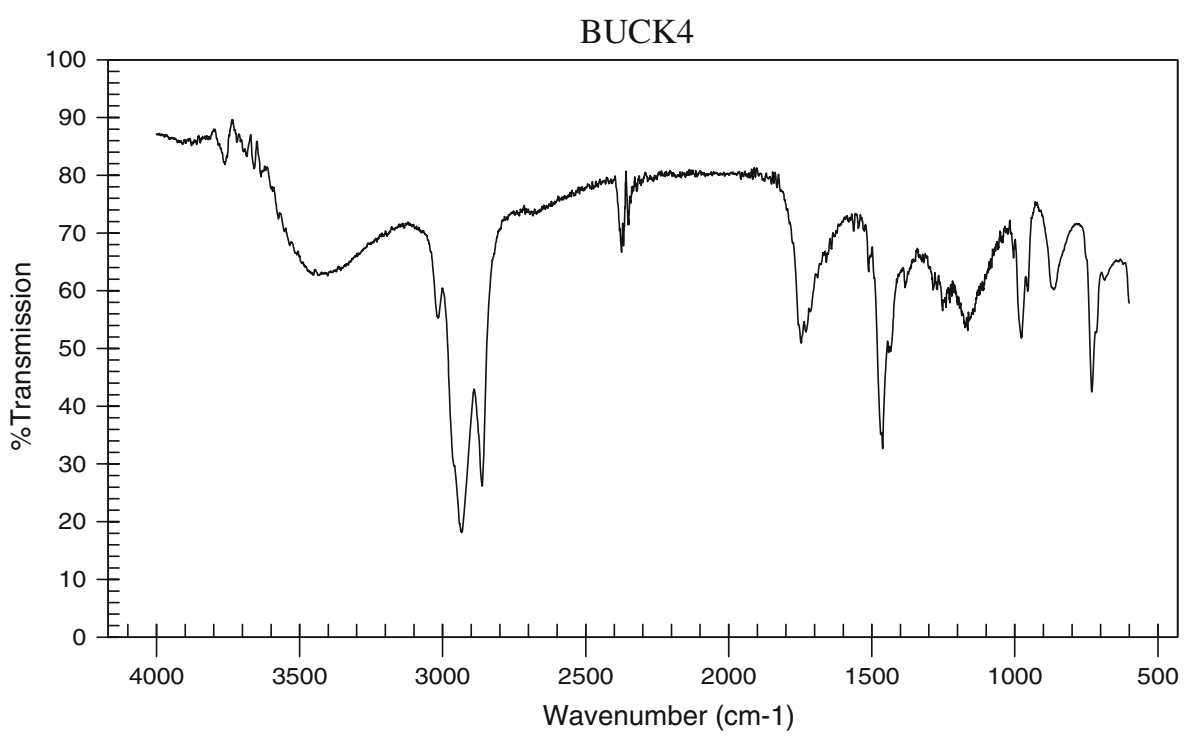

buck2

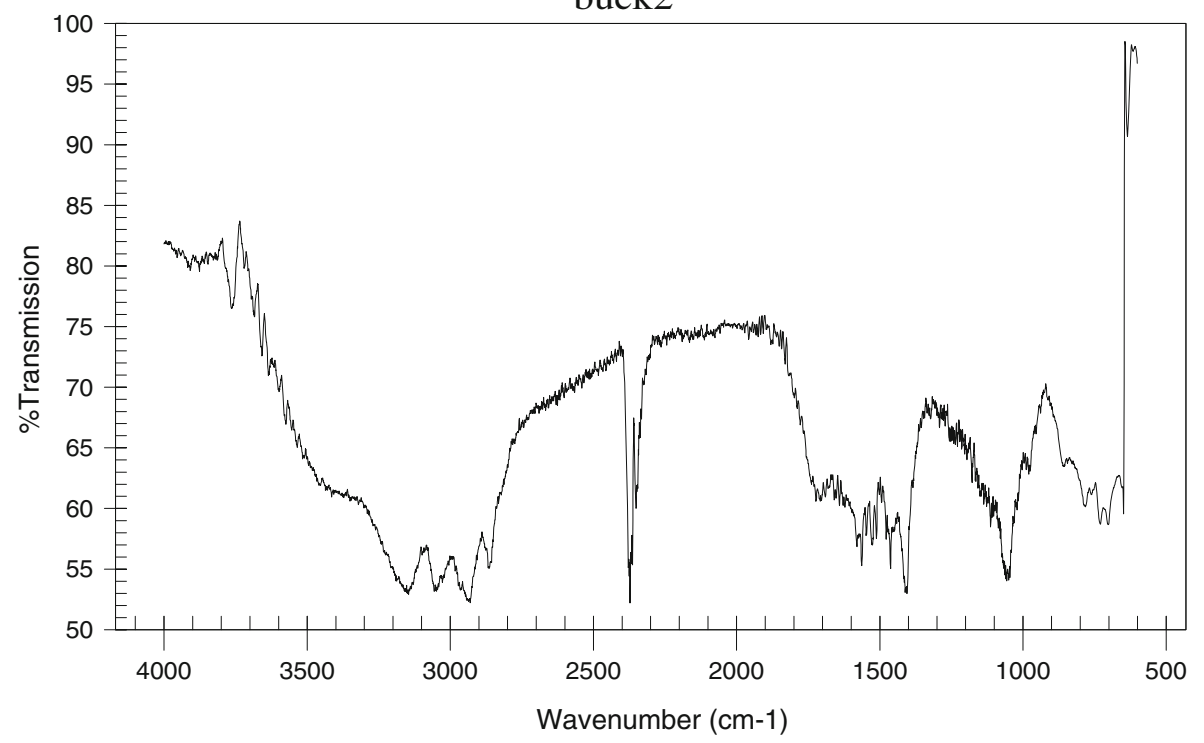

Fig. 5 Infrared spectrum of ammonium caster oil sulfonate (ACS)

Table 3 Assignment of prominent infrared absorption bands in castor oil (Fig. 4) and ammonium caster oil sulfonate (Fig. 5)

\begin{tabular}{llllll}
\hline Compound & \multicolumn{5}{l}{ Infrared absorption $\left(\mathrm{cm}^{-1}\right)$} \\
\cline { 2 - 6 } & $-\mathrm{S}$ & $\mathrm{N}-\mathrm{H}$ & $\mathrm{SO}_{3-}$ & $\mathrm{C}-\mathrm{H}$ & $\mathrm{CH}_{2}$ \\
\hline $\begin{array}{l}\text { Caster oil } \\
\text { Ammonium }\end{array}$ & - & - & - & 680,1450 & 2995,2880 \\
$\begin{array}{l}\text { caster } \\
\text { oil sulfonate }\end{array}$ & 1650 & 315,350 & 1220,1050 & 680,1450 & 2995,2880 \\
\hline
\end{tabular}

the experimental work with the commercially available $\mathrm{R}_{\mathrm{P}} / 6000$ demulsifier and the prepared ammonium caster oil sulfonate (ACS) demulsifier:
1) Water separation increases with increasing separation time for both demulsifiers tested.

2) There is a limiting water separation, which depends on the concentration of the demulsifier.

3) Water separation efficiency increases with increasing dose of demulsifiers.

Acknowledgments This work has been supported by the University of Basrah, Polymer research center, chemistry department. The author gratefully acknowledges the support from the Head of the Department.

Open Access This article is distributed under the terms of the Creative Commons Attribution License which permits any use, distribution, and reproduction in any medium, provided the original author(s) and the source are credited. 


\section{References}

Berger D, Hsu K (2000) Patent US 6,043,391

Durrieu M, Havre L (1992) Patent US 5,154,857

Gary JH, Handwerk GE (1975) Petroleum refining, vol 5, Chap 12 Golden R (2003) Patent US 6,545,181 B1

Hobson GD (1988) Modern petroleum technology, vol 2, p 586
Institute of Petroleum (1990) Standard methods for analysis and testing of petroleum and related products, vol 11. Wiley, pp 665-785

Kirk O (1988) Encyclopedia of chemical technology, vol 19

Lorenz H, Martin H (1976) Patent US 3,974,220

Ptister F, Antoine S (2000) Patent US 6,022,601

Silverstein RM, Basslar GC (1981) Spectrometric identification of organic compounds, 4th edn. pp 103-285 